\title{
UJI MACAM BIBIT DAN DOSIS PUPUK KANDANG AYAM TERHADAP KERUSAKAN UMBI HAMA BOLENG (Cylas formicarius) PADA TANAMAN UBI JALAR
}

\author{
Arief Chandra Kusuma ${ }^{1 *}$, Sartono ${ }^{1}$, Kharis Triyono ${ }^{1}$ \\ ${ }^{1}$ Program Studi Agroteknologi, Fakultas Pertanian, Universitas Slamet Riyadi, Jl. Sumpah \\ Pemuda No. 18 Kadipiro, Banjarsari, Kota Surakarta, Jawa Tengah-57136 \\ 1*ariv990@gmail.com
}

\begin{abstract}
S
Research on "TEST OF SEEDS AND DOSAGE OF CHICKEN FERTILIZER ON THE DAMAGE OF (Cylas formicarius) IN SWEET POTATO PLANTS" was carried out from November 1, 2018 to February 15, 2019, located in Tegalrejo Hamlet, Kuto Village, Kerjo Subdistrict, Karanganyar, Central Java. The purpose of this study was to examine the types of seedlings and students of chicken manure to damage tuber tuber(Cylas formicarius) to sweet potato plants. This study uses a Complete Randomized Block Design (RAKL) consisting of 2 factors: The first factor is the type of seed (B), consisting of 2 types, namely: $B_{1}:$ Seed buds, $B_{2}:$ Stem seedlings. The second factor is the dose of chicken manure $(K)$, which consists of 5 levels, namely: $K_{0}: 0.0$ gram / plant, $K_{1}: 176$ grams / plant, $K_{2}$ : 208 grams / plant, $K_{3}: 240$ grams / plant, $K_{4}: 272$ grams / plant. Of the two factors, 10 combinations of treatments were obtained, each of which was repeated 3 times so that the overall treatment combination was obtained 30. Data were analyzed using Variety Analysis, followed by Honest Real Difference Test at $5 \%$ real level. Based on the results of the research and discussion, conclusions can be drawn that the use of stem parts does not significantly affect the damage to tubers caused by tart pests because the stem part of the stem has a hard structure different from the shoots that have soft structures, the average yield parameters the following parameters show that the intensity of the lowest pest attack is in the treatment of stem parts, which is $22.37 \%$, the lowest number of sweet potatoes is 0.58 sweet potatoes, the lowest weight of sweet potato is found in the shoots of 71.64grams, the highest weight of sweet potatoes is on the stem part is 608.33 grams, the lowest number of healthy sweet potatoes is 4.75 sweet potatoes.
\end{abstract}

Keywords: Sweet potato, Cylas formicarius, Chicken manure

\begin{abstract}
ABSTRAK
Penelitian tentang "UJI MACAM BIBIT DAN DOSIS PUPUK KANDANG AYAM TERHADAP KERUSAKAN UMBI HAMA BOLENG (Cylas formicarius) PADA TANAMAN UBI JALAR" telah dilaksanakan mulai tanggal 01 November 2018 sampai tanggal 15 Pebruari 2019, bertempat di Dusun Tegalrejo, Desa Kuto, Kecamatn Kerjo, Kabuaten Karanganyar, Jawa Tengah. Tujuan penelitian ini untuk menguji macam bibit dan dosis pupuk kandang ayam terhadap kerusakan umbi hama boleng (Cylas formicarius) pada tanaman ubi jalar. Penelitian ini menggunakan Rancangan Acak Kelompok Lengkap (RAKL) terdiri dari 2 faktor : Faktor pertama adalah macam bibit (B), terdiri dari 2 macam, yaitu ; $\mathrm{B}_{1}$ : Bibit bagian pucuk, $\mathrm{B}_{2}$ : Bibit bagian batang. Faktor kedua adalah dosis pupuk kandang ayam $(\mathrm{K})$, terdiri dari 5 taraf, yaitu $: \mathrm{K}_{0}: 0,0$ gram/tanaman, $\mathrm{K}_{1}: 176$ gram/tanaman, $\mathrm{K}_{2}: 208$ gram/tanaman, $K_{3}: 240$ gram/tanaman, $K_{4}: 272$ gram/tanaman Dari kedua faktor tersebut diperoleh 10 kombinasi perlakuan yang masing-masing diulang 3 kali sehingga keseluruhan diperoleh 30 kombinasi perlakuan. Data dianalisis menggunakan Analisis Ragam, dilanjutkan dengan Uji beda Nyata Jujur pada taraf nyata 5\%. Berdasarkan hasil penelitian dan pembahasan maka dapat disusun kesimpulan yaitu penggunaan bibit bagian batang tidak
\end{abstract}


berpengaruh nyata dalam meningkatkan kerusakan pada umbi yang disebabkan hama boleng karena bibit bagian batang mempunyai struktur yang keras berbeda dengan bibit bagian pucuk yang mempunyai struktur lunak, rata-rata hasil parameter-parameter berikut menunjukkan bahwa intensitas serangan hama terendah terdapat pada perlakuan bibit bagian batang yaitu $22,37 \%$, jumlah ubi boleng terendah 0,58 ubi pertanaman, berat ubi boleng terendah terdapat pada perlakuan bibit bagian pucuk yaitu 71,64gram, berat ubi sehat tertinggi terdapat pada bagian batang yaitu 608,33 gram, jumlah ubi sehat terendah 4,75 ubi pertanaman

Kata kunci : Ubi jalar, Cylas formicarius, pupuk kandang ayam

\section{PENDAHULUAN}

Ubi jalar (Ipomeabatatas L.) atau dikenal juga dengan istilah ketela rambat merupakan tanaman yang termasuk ke dalam jenis tanaman palawija, dapat berfungsi sebagai pengganti bahan makanan pokok (beras) karena merupakan sumber karbohidrat. Provinsi Jawa Barat merupakan daerah sentra dan penghasil komoditas ubi jalar terbesar di Indonesia. Selama periode 2005-2009, produksi ubi jalar Jawa barat meningkat dengan rata-rata $1,90 \%$ / tahun.

Pupuk kandang adalah pupuk yang berasal dari kandang hewan ternak baik yang berupa kotoran padat ataupun cair. Kelebihan dari pupuk organik cair adalah dapat secara cepat mengatasi defisiensi hara, tidak bermasalah dalam pencucian hara dan mampu menyediakan hara secara cepat. Untuk mendukung keberhasilan dalam pertumbuhan ubi pada tanaman ubi jalar maka perlu adanya upaya pemupukan dengan harapan hasil yang diperoleh maksimum. (Sutejo, 2008). Bahan perbanyakan tanaman ubi jalar berupa stek paling cocok untuk tujuan produksi umbi. Pertumbuhan tanaman ubi jalar asal stek pucuk/batang lebih seragam, selain itu kemampuan untuk menghasilkan umbi relatif lebih baik jika dibandingkan dengan stek dari umbi atau biji. (Basuki dkk., 1987).

Kumbang Cylas formicarius menjadi masalah yang berpengaruh untuk peningkatan mutu ubi (Anonim 1991) dan tersebar di seluruh dunia seperti Amerika, Kenya, dan Indonesia. Serangan $C$. formicarius tidak hanya di lapangan tetapi juga menimbulkan kerusakan yang nyata di penyimpanan. Umbi yang terserang kumbang Cylas formicarius akan rusak dan membuat senyawa terpenoid yang menjadikan umbi terasa pahit dan tidak layak untuk dikonsumi (Jansson et al. 1987).

\section{METODE PENELITIAN}

Percobaan penelitian telah dilakukan pada tanggal 01 November 2018 - 15 Februari 2019, bertempat di Dusun Tegalrejo, Desa Kuto, Kecamatn Kerjo, Kabupaten Karanganyar, Jawa Tengah. Penelitian ini menggunakan Rancangan Acak Kelompok Lengkap (RAKL) faktorial dengan menggunakan macam bibit (B) terdapat 2 macam yaitu : bibit bagian pucuk $\left(\mathrm{B}_{1}\right)$, bibit bagian batang $\left(\mathrm{B}_{2}\right)$.

Penanaman bibit membersihkan lahan terlebih dahulu dari rerumputan menggunakan sabit dan cangkul lalu tanah diolah menggunakan cangkul untuk membolak balik tanah supaya gembur lalu diamkan selama 1 minggu. Membuat guludan sambil membersihkan rerumputan yang muncul, dengan ukuran lebar bawah $60 \mathrm{~cm}$, tinggi $30 \mathrm{~cm}$, jarak antar guludan 70 $\mathrm{cm}$,merapikan guludan sambil memperbaiki saluran.

Penanaman terlebih dahulu memotong bibit sepanjang $25 \mathrm{~cm}$ dan memilih bibit untuk ditanam dan disesuaikan kegunaan bibit yang akan digunakan, bibit direndam dengan hormon auksin sehari sebelum penanaman $1 \mathrm{ml}$ dengan air $1 \mathrm{lt}$. Perlakuan jenis bibit B1 bagian pucuk dengan panjang bibit $25 \mathrm{~cm}$ dan B2 Bagian batang dengan panjang $25 \mathrm{~cm}$

Bibit dipersiapkan sehari sebelum penanaman. Penanaman dilakukan sore hari atau pada saat matahari condong ke barat untuk menghindari penguapan yang berlebihan. Sebelum stek ditanam guludan dibasahi. Cara penanaman buat lubang di tengah - tengah guludan menggunakan sabit dengan jarak tanam $25 \mathrm{~cm}$ didalam barisan, bibit yang sudah siap di tanam pada lubang tersebut kemudian ditutup kembali 
menggunakan tanah, satu lubang satu stek. Stek ditanam dengan posisi tegak lurus $90^{\circ}$ didalam tanah dengan kedalaman 2 ruas.

Dosis pupuk yang diberikan (100 kg urea/ha) $+(50 \mathrm{~kg} \mathrm{TSP} / \mathrm{ha})+(100 \mathrm{~kg} \mathrm{KCL} / \mathrm{ha})$. Sedangkan pemberian pupuk yang ke dua diberikan pada saat tanaman berumur 45 hari setelah tanam.

Cara pemberian dengan cara ditugal, dibuat lubang dengan tugal di sepanjang guludan sejauh $7 \mathrm{~cm}-10 \mathrm{~cm}$ dari batang tanaman, sedalam $5 \mathrm{~cm}-7 \mathrm{~cm}$, kemudian masukan pupuk kedalam lubang sambil ditutup tanah tipis. Perlakuan dosis pupuk kandang ayam K0 dengan dosis pemberian pupuk 0,0 gram, K1 dengan dosis pemberian pupuk 176 gram K2 dengan dosis pemberian pupuk 208 gram, K3 dengan dosis pemberian pupuk 240 gram, dan K4 dengan dosis pemberian pupuk 272 gram.

Variable pengamatan penelitian ini yaitu intensitas serangan hama, morfologi hama boleng, jumlah ubi sehat pertanaman, jumlah ubi boleng pertanaman, berat segar ubi sehat, berat segar ubi boleng. Setelah didapat data kemudian dianalisis dengan $\mathrm{Uji}$ BNJ taraf 5\%.

\section{HASIL DAN PEMBAHASAN}

Hasil perlakuan macam bibit dan dosis pupuk kandang ayam untuk intensitas serangan hama pada tabel 1 dapat dilihat bahwa tidak ada pengaruh nyata pada intensitas serangan hama boleng

Tabel 1. Rata - rata intensitas serangan hama boleng

\begin{tabular}{cccccc}
\hline Macam Bibit & \multicolumn{5}{c}{ Dosis Pupuk Kandang Ayam ( K ) } \\
\cline { 2 - 6 } ( B ) & $\mathrm{K}_{0}$ & $\mathrm{~K}_{1}$ & $\mathrm{~K}_{2}$ & $\mathrm{~K}_{3}$ & $\mathrm{~K}_{4}$ \\
\hline $\mathrm{B}_{1}$ & $27,61 \mathrm{a}$ & $32,48 \mathrm{a}$ & $50,00 \mathrm{a}$ & $33,41 \mathrm{a}$ & $49,95 \mathrm{a}$ \\
$\mathrm{B}_{2}$ & $22,37 \mathrm{a}$ & $49,95 \mathrm{a}$ & $38,47 \mathrm{a}$ & $33,41 \mathrm{a}$ & $27,13 \mathrm{a}$ \\
\hline
\end{tabular}

Keterangan : Purata intensitas serangan hama pertanaman yang diikuti huruf yang sama berarti berbeda tidak nyata pada taraf BNJ 5\%

Dari tabel diatas dapat diketahui bahwa intensitas serangan hama tertinggi adalah pada perlakuan Bibit $\mathrm{B}_{1}$ yaitu bagian pucuk dengan panjang $25 \mathrm{~cm}$ dan pupuk kandang ayam $\mathrm{K}_{2}$ yaitu pemberian pupuk kandang ayam dengan dosis 208 gram pertanaman dan intensitas serangan hama terendah adalah pada perlakuan bibit bagian batang $\mathrm{B}_{2}$ yaitu bagian batang dengan panjang $25 \mathrm{~cm}$ dan pupuk kandang ayam $\mathrm{K}_{0}$ yaitu pemberian pupuk kandang ayam dengan dosis 0 gram pertanaman.

Hasil penelitian di lokasi penelitian didapati kumbang Cylas formicarius sedang berada di bagian atas tanah dengan bentuk menyerupai semut, mempunyai abdomen, tungkai, dan caput yang panjang dan kurus, kepala berwarna hitam, antena, thoraks, dan tungkai oranye sampai cokelat kemerahan, abdomen dan elytra biru metalik. Supriyatin
(2001) menyatakan bahwa kumbang Cylas formicarius terdapat kepala, mempunyai abdomen, dan sayapnya berwarna biru metalik, sedangkan kaki dan dadanya coklat. Pada bagian tungkai mempunyai cincin di sekeliling tibia, kumbang Cylas formicarius mempunyai antena mempunyai sepuluh ruas. Terdapat perbedaan antara kumbang jantan dan kumbang betina yaitu terletak pada antena, antena kumbang jantan berbentuk seperti benang, dan panjangnya lebih dari dua kali panjang flagelum. Antena kumbang betina berbentuk seperti gada, jarak antara ruas pada antena dua pertiga dari panjang flagelum, abdomen kumbang jantan lebih besar daripada kumbang betina. Hasil perlakuan macam bibit dan dosis pupuk kandang ayam pada tabel 2 dapat dilihat bahwa tidak ada pengaruh nyata pada jumlah ubi sehat pertanaman

Tabel 2. Rata - rata jumlah ubi sehat pertanaman

\begin{tabular}{cccccc}
\hline \multirow{2}{*}{ Macam Bibit ( B ) Dosis Pupuk Kandang Ayam ( K ) } \\
\cline { 2 - 6 } & $\mathrm{K}_{0}$ & $\mathrm{~K}_{1}$ & $\mathrm{~K}_{2}$ & $\mathrm{~K}_{3}$ & $\mathrm{~K}_{4}$ \\
\hline $\mathrm{B}_{1}$ & 0,75 & 1,00 & 1,75 & 1,08 & 1,67 \\
$\mathrm{~B}_{2}$ & 0,58 & 1,42 & 1,08 & 1,00 & 0,83 \\
\hline
\end{tabular}

Keterangan : Purata jumlah ubi pertanaman yang diikuti huruf yang sama berarti berbeda tidak nyata pada taraf BNJ $5 \%$ 
Dari tabel diatas dapat diketahui bahwa rata rata tertinggi jumlah ubi sehat pertanaman adalah pada perlakuan Bibit $\mathrm{B}_{1}$ yaitu bagian pucuk dengan panjang $25 \mathrm{~cm}$ dan pupuk kandang ayam $\mathrm{K}_{2}$ yaitu pemberian pupuk kandang ayam dengan dosis 208 gram pertanaman dan intensitas serangan hama terendah pada dua perlakuan bibit bagian batang $\mathrm{B}_{2}$ dan bibit bagian pucuk $\mathrm{B}_{1}$ dengan panjang $25 \mathrm{~cm}$ pupuk kandang ayam $\mathrm{K}_{0}$ yaitu pemberian pupuk kandang ayam dengan dosis 0 gram pertanaman. Anonim (2004) mengatakan bahwa hama boleng biasanya meletakkan telurnya di bibit bagian batang ubi jalar, setelah telur berhasil menjadi larva kemudian larva tersebut mulai bergerak menggerek umbi himgga larva tersebut menjadi kumbang dewasa. Hasil perlakuan macam bibit dan dosis pupuk kandang ayam pada tabel 3 dapat dilihat bahwa tidak ada pengaruh nyata pada jumlah ubi boleng pertanaman

Tabel 3 Rata - rata jumah ubi boleng pertanaman

\begin{tabular}{cccccc}
\hline \multirow{2}{*}{ Macam Bibit ( B ) Dosis Pupuk Kandang Ayam ( K ) } \\
\cline { 2 - 6 } & $\mathrm{K}_{0}$ & $\mathrm{~K}_{1}$ & $\mathrm{~K}_{2}$ & $\mathrm{~K}_{3}$ & $\mathrm{~K}_{4}$ \\
\hline $\mathrm{B}_{1}$ & $6,25 \mathrm{a}$ & $6,17 \mathrm{a}$ & $6,92 \mathrm{a}$ & $6,42 \mathrm{a}$ & $5,75 \mathrm{a}$ \\
$\mathrm{B}_{2}$ & $6,25 \mathrm{a}$ & $6,25 \mathrm{a}$ & $5,83 \mathrm{a}$ & $4,75 \mathrm{a}$ & $5,00 \mathrm{a}$ \\
\hline
\end{tabular}

Keterangan : Purata jumlah ubi boleng pertanaman yang diikuti huruf yang sama berarti berbeda tidak nyata pada taraf BNJ $5 \%$

Dari tabel diatas dapat diketahui bahwa rata rata tertinggi jumlah ubi boleng pertanaman adalah pada perlakuan Bibit $\mathrm{B}_{1}$ yaitu bagian pucuk dengan panjang $25 \mathrm{~cm}$ dan pupuk kandang ayam $\mathrm{K}_{4}$ yaitu pemberian pupuk kandang ayam dengan dosis 272 gram pertanaman dan jumlah ubi boleng terendah adalah pada perlakuan bibit bagian batang $\mathrm{B}_{1}$ yaitu bagian batang dengan panjang $25 \mathrm{~cm}$ dan pupuk kandang ayam $\mathrm{K}_{0}$ yaitu pemberian pupuk kandang ayam dengan dosis 0 gram pertanaman. Hasil perlakuan macam bibit dan dosis pupuk kandang ayam pada tabel 4 dapat dilihat bahwa tidak ada pengaruh nyata pada jumlah ubi boleng pertanaman

Tabel 4 Rata - rata berat segar ubi sehat pertanaman

\begin{tabular}{cccccc}
\hline \multirow{2}{*}{ Macam Bibit ( B ) } & \multicolumn{5}{c}{ Dosis Pupuk Kandang Ayam ( K ) } \\
\cline { 2 - 6 } & $\mathrm{K}_{0}$ & $\mathrm{~K}_{1}$ & $\mathrm{~K}_{2}$ & $\mathrm{~K}_{3}$ & $\mathrm{~K}_{4}$ \\
\hline $\mathrm{B}_{1}$ & $566,67 \mathrm{a}$ & $675,00 \mathrm{a}$ & $575,00 \mathrm{a}$ & $583,33 \mathrm{a}$ & $337,50 \mathrm{a}$ \\
$\mathrm{B}_{2}$ & $537,50 \mathrm{a}$ & $520,83 \mathrm{a}$ & $608,33 \mathrm{a}$ & $641,67 \mathrm{a}$ & $558,33 \mathrm{a}$ \\
\hline
\end{tabular}

Keterangan : Purata berat ubi sehat pertanaman yang diikuti huruf yang sama berarti berbeda tidak nyata pada taraf BNJ $5 \%$

Dari tabel diatas dapat diketahui bahwa rata rata tertinggi berat ubi sehat pertanaman adalah pada perlakuan Bibit $\mathrm{B}_{1}$ yaitu bagian pucuk dengan panjang $25 \mathrm{~cm}$ dan pupuk kandang ayam $\mathrm{K}_{1}$ yaitu pemberian pupuk kandang ayam dengan dosis 176 gram pertanaman dan berat ubi sehat pertanaman terendah adalah pada perlakuan bibit bagian batang $\mathrm{B}_{1}$ yaitu bagian batang dengan panjang $25 \mathrm{~cm}$ dan pupuk kandang ayam $\mathrm{K}_{4}$ yaitu pemberian pupuk kandang ayam dengan dosis 272 gram pertanaman. Hasil perlakuan macam bibit dan dosis pupuk kandang ayam pada tabel 5 dapat dilihat bahwa tidak ada pengaruh nyata pada jumlah ubi boleng pertanaman.

Tabel 6 Rata - rata berat ubi boleng pertanaman

\begin{tabular}{|c|c|c|c|c|c|}
\hline \multirow{2}{*}{ Macam Bibit ( B ) Dosis Pupuk Kandang Ayam ( K ) } \\
\cline { 2 - 6 } & $\mathrm{K}_{0}$ & $\mathrm{~K}_{1}$ & $\mathrm{~K}_{2}$ & $\mathrm{~K}_{3}$ & $\mathrm{~K}_{4}$ \\
\hline $\mathrm{B}_{1}$ & $71,67 \mathrm{a}$ & $162,50 \mathrm{a}$ & $200,00 \mathrm{a}$ & $120,00 \mathrm{a}$ & $287,50 \mathrm{a}$ \\
\hline $\mathrm{B}_{2}$ & $100,83 \mathrm{a}$ & $191,67 \mathrm{a}$ & $149,58 \mathrm{a}$ & $170,83 \mathrm{a}$ & $100,83 \mathrm{a}$ \\
\hline
\end{tabular}

Keterangan : Purata berat ubi boleng pertanaman yang diikuti huruf yang sama berarti berbeda tidak nyata pada taraf BNJ $5 \%$ 
Dari tabel diatas dapat diketahui bahwa rata rata tertinggi berat segar ubi boleng pertanaman adalah pada perlakuan Bibit $B_{1}$ yaitu bagian pucuk dengan panjang $25 \mathrm{~cm}$ dan pupuk kandang ayam $\mathrm{K}_{4}$ yaitu pemberian pupuk kandang ayam dengan dosis 276 gram pertanaman dan rata-rata berat ubi boleng pertanaman terendah adalah pada perlakuan bibit bagian batang $\mathrm{B}_{1}$ yaitu bagian batang dengan panjang $25 \mathrm{~cm}$ dan pupuk kandang ayam $\mathrm{K}_{0}$ yaitu pemberian pupuk kandang ayam dengan dosis 0 gram pertanaman.

\section{KESIMPULAN}

Berdasarkan hasil penelitian dan pembahasan maka dapat disusun kesimpulan yaitu penggunaan bibit bagian batang tidak berpengaruh nyata dalam meningkatkan kerusakan pada umbi yang disebabkan hama boleng karena bibit bagian batang mempunyai struktur yang keras berbeda dengan bibit bagian pucuk yang mempunyai struktur lunak, rata-rata hasil parameterparameter berikut menunjukkan bahwa intensitas serangan hama terendah terdapat pada perlakuan bibit bagian batang yaitu $22,37 \%$, jumlah ubi boleng terendah 0,58 ubi pertanaman, berat ubi boleng terendah terdapat pada perlakuan bibit bagian pucuk yaitu 71,64gram, berat ubi sehat tertinggi terdapat pada bagian batang yaitu 608,33 gram ,jumlah ubi sehat terendah 4,75 ubi pertanaman.

\section{DAFTAR PUSTAKA}

Anonim. 2017. Bagaimana mengendalikan hama Boleng pada Ubi Jalar. Badan Litbang Pertanian. http://www.litbang.pertanian.go.id/b erita/one/2783/
Anonim. 2007. Jumlah produksi ubi jalar di Jawa Barat. Bandung : Badan Pusat Statistik Provinsi Jawa Barat.

Basuki, N., Y. Widodo, Sudaryono, dan S. Brotonegoro. 1987. Penelitian teknik tanaman ubi jalar. Mimeograph. hlm. $1-23$.

Jafar, mohammad H.,2004. Prospek Bisnis Ubi Jalar. Jakarta : PT. Pustaka Sinar Harapan.

Rajamma, P. 1983. Biology and bionomics of Sweet potato weevil Cylas formicarius. Insect Ecology and Resources Management. India. 87-92

Supriyatin. 2001. Hama boleng pada ubi jalar dan pengendaliannya. Palawija 2. 22-29.

Soemarno. 1981. Pengkajian singkat kesuburan ubi jalar. Malang : Departemen Ilmu Tanah. Fakultas Pertanian Universitas Brawijaya.

Sutejo, M. M.dan A. G. Kartasapoetra. 2002. Pupuk dan Cara Pemupukan. Jakarta : Bina Aksara. Hlm 177.

Widowati, L.R., Sri Widati, U. Jaenudin, dan W. Hartatik. 2005. Pengaruh Kompos Pupuk Organik yang Diperkaya dengan Bahan Mineral dan Pupuk Hayati terhadap Sifatsifat Tanah, Serapan Hara dan Produksi Sayuran Organik. Laporan Proyek Penelitian Program Pengembangan Agribisnis, Balai Penelitian Tanah, TA 2005 (Tidak dipublikasikan). 